\title{
Experimental and Numerical Investigation of the Ground Shock Coupling Factor for Near-Surface Detonations
}

\author{
Timothy W. Shelton, ${ }^{1}$ John Q. Ehrgott Jr., ${ }^{1}$ Ramon J. Moral, ${ }^{1}$ and Michele Barbato ${ }^{2}$ \\ ${ }^{1}$ U.S. Army Engineer Research and Development Center, Impact and Explosion Effects Branch, Geotechnical and Structures Laboratory, \\ 3909 Halls Ferry Road, Vicksburg, MS 39180-6199, USA \\ ${ }^{2}$ Louisiana State University, 3418 H Patrick F. Taylor Hall, Baton Rouge, LA 70803, USA
}

Correspondence should be addressed to Timothy W. Shelton; timothy.w.shelton@erdc.dren.mil

Received 29 January 2013; Accepted 6 February 2014; Published 26 March 2014

Academic Editor: Vadim V. Silberschmidt

Copyright ( 2014 Timothy W. Shelton et al. This is an open access article distributed under the Creative Commons Attribution License, which permits unrestricted use, distribution, and reproduction in any medium, provided the original work is properly cited.

\begin{abstract}
This paper presents the results of recent ground shock experiments conducted by the U.S. Army Engineer Research and Development Center to further investigate the adequacy of the coupling factor approach to shallow-buried or near-surface detonations. Comparisons between these recent experimental results and results of numerical simulations of the ground shock propagation in soil are presented. It was found that the coupling factor curve currently adopted in design of buried structures does not accurately represent the actual ground shock propagation in soil and that different coupling factor curves are needed for different physical quantities of interest in design. The results presented in this paper also suggest that the coupling factor curves are functions of several parameters in addition to the depth of burial and that numerical simulations can capture reasonably well the ground shock propagation of soil stresses and particle velocities.
\end{abstract}

\section{Introduction}

The U.S. military has many important deeply buried hardened facilities that must be capable of surviving the effects of conventional weapon attacks, which can result in the detonation of buried explosives in close proximity to the buried structure. These structures are designed to withstand ground shock induced by an explosive event that could occur any distance from the structure, either aboveground or belowground, thereby providing safe harbor for personnel. To achieve a reliable design, accurate methods are needed to predict the ground shock (i.e., radial soil stresses and particle velocities) that propagates from the explosive source to the buried structure. For aboveground detonations, the ground shock induced to the buried structure is minimal, as the vast majority of the explosive energy is transmitted as airblast. As the detonation point moves towards and eventually below the ground surface, the energy transmitted into the ground, and hence the resulting ground shock, increases until a maximum ground shock is produced at a specific depth. The distance from the ground surface to the center of gravity of the detonating charge, considered as positive for below ground explosions, is called depth of burial (DOB). The maximum ground shock is produced at a DOB that is referred to as a "fully coupled" DOB. By definition, the fully coupled DOB is the depth at which burying the bomb any additional amount will not result in additional ground shock transmission. The ground shock for detonations occurring at depths at or below the fully coupled DOB (fully coupled detonations) is quite predictable and can be adequately calculated for a given explosive mass [1]. For detonations that occur near or slightly above the ground surface (near-surface detonations), the corresponding ground shock becomes more difficult to predict. This limitation in ground-shock-induced load predictability presents designers of buried protective structures a dilemma because many potential threats may detonate in these areas and produce unpredictable structural loads.

The current method for predicting ground shock phenomena produced by detonations at or slightly below the ground surface consists of applying a reduction coefficient to the magnitude of the ground shock effect produced by a fully contained or deeply buried weapon. This reduction 
coefficient, commonly called the "coupling factor," is used to account for the energy lost to the atmosphere from a nearsurface detonation. In the historical literature, the coupling factor is represented as a function of the material in which the weapon is buried and the scaled depth of burial (DOB) of the detonation and is defined as the ratio of the ground shock magnitude from a near-surface detonation to that from a fully coupled detonation:

$$
f=\frac{\left(P, V_{p}, d_{p}, I, a\right)_{\text {near-surface }}}{\left(P, V_{p}, d_{p}, I, a\right)_{\text {fully coupled }}}
$$

where $P$ denotes pressure, $V_{p}$ denotes particle velocity, $d_{p}$ denotes particle displacement, $I$ denotes impulse, and $a$ denotes acceleration. The use of a single coupling factor for all design quantities is based on the relationships among these quantities in the idealized case of a plane shock wave passing through an infinite elastic medium [2]. Recent research indicates that the current methodology for computing and applying coupling factors to account for reductions in ground shock due to near-surface detonations is limited and in need of improvements and that different coupling factors may be needed for soil stress and particle velocity in lieu of the single factor presently used for both quantities [3].

This paper provides a short historical review of the coupling factor method and results of historical field experiments as well as their interpretation in terms of coupling factor for different design quantities. In addition, this paper presents the results of more recent field experiments conducted to quantify $f$ for a particular soil type as well as a comparison of these experimental results with results of preliminary highperformance computing (HPC) calculations.

\section{Background and Historical Experiment Data}

Lampson [2] is credited with conducting during World War II initial ground shock tests with buried charges in multiple soil types. From this work, the principle of cube root scaling was developed. Following his work, several other researchers conducted experimental studies to extend the knowledge of ground shock data pertaining to other soil types and even rocks [4-9]. Many of these studies were conducted during the Cold War era and were focused on potential nuclear events. These events were often conducted in media such as granite that are not representative of those where buried structures are found [7]. Additionally, accelerometers and soil stress gages were somewhat unreliable, and in many cases, mechanical failure or cable failure led to incomplete or questionable data. In 1986, Drake and Little [10] presented a paper that summarized the findings of the previous works and provided an overview of the empirical findings in the U.S. Army design manual TM 5-855-1, Fundamentals of Protective Design for Conventional Weapons [11]. Drake and Little outlined the fundamentals of ground shock and defined several variables that affect the intensity of the loading. These factors included weapon size, distance from ground zero to target, mechanical properties of soil, and depth of penetration of the weapon. They also pointed out that soil properties are the least predictable of the factors and that different soil properties may cause ground shock intensities to vary significantly, up to two orders of magnitude. The main technical presentations by Drake and Little included a means of making crude ground shock predictions based on the seismic velocity, $c$, of a soil and the outline of the ground shock coupling factor, $f$, which is a scale factor used to reduce the ground shock computed from a fully buried charge to account for a shallow burial. Using the seismic velocity, predictions for time of arrival of the shock front $\left(t_{a}\right)$, rise time to the peak $\left(t_{r}\right)$, peak stress $\left(P_{0}\right)$, peak velocity $\left(V_{0}\right)$, peak acceleration $\left(a_{0}\right)$, and peak displacement $\left(d_{0}\right)$ could be made. Functions were also provided to calculate the stress and particle velocity histories as a function of time.

The existing coupling factor methodology for soil is based on a simple plot of the coupling factor versus the scaled DOB, $d$, which is defined as

$$
d=\frac{\mathrm{DOB}}{W^{1 / 3}}
$$

where $\mathrm{DOB}$ is measured in meters and $W$ is the mass of the explosive measured in kilograms. The coupling factor presented in [11] ranges in value from 0.14 to 1.0 and depends on the material (e.g., soil, concrete, or air) in which the detonation occurs. This coupling factor, $f$, is multiplied by the calculated peak values for soil stress and particle velocity for a fully coupled detonating charge of the same type and mass to produce both a stress and particle velocity time history that can be used in structural analysis. The use of a single curve for any type of soil is based on the assumption that there is a negligible difference in ground shock transmissivity for different soil types. This assumption implies that blast propagates similarly and produces similar loads for all soils regardless of granularity, cohesion, particle size, density, or moisture content. Drake et al. [12] reformulated the empirical equations used to develop the original coupling factor curve but did not modify the curve itself to include multiple soil types. Various field experiments, the fundamentals of soil mechanics, and multiple publications $[3,13,14]$ suggest that the assumption that soil type does not influence blast propagation is inaccurate and should be refined to include multiple curves corresponding to categorical soil definitions. Ehrgott Jr. [3] suggests that a single coupling factor may not be applicable to both particle velocity and soil stress in certain soils. An additional limitation affecting the coupling factor approach is that the coupling factor is applied only to the magnitudes of stress and particle velocity waveforms and does not affect the time dimension of the stress and particle velocity waveforms. This means the coupling factor changes neither the rise time to peak stress and particle velocity nor the time duration of the load from that calculated for a fully coupled explosive event. Therefore, both the peak values of the stress and particle velocity and the decay and duration of the associated time histories for blast loads that are not fully coupled have potential deficiencies that need to be addressed.

In the last few decades, several field experiments were conducted with mixed results in an attempt to better quantify the relationships of DOB and height of burst on induced ground shock. The most notable effort to obtain a greater 
understanding of the surface rarefaction effects on compression waves in soils was a series of field experiments funded by the Defense Nuclear Agency beginning in the late 1980s. The experiments were named Midnight Hour 1 (MH1), Midnight Hour 2 (MH2), Husky Jaguar 1 (HJ1), and Husky Jaguar 2 (HJ2). All four experiments were conducted using an explosive charge of nitromethane and a carefully controlled backfill of Socorro plaster sand. While the explosive charge mass for each event was held constant throughout the four experiments, other factors, including $\mathrm{DOB}$, were varied to some extent. The $\mathrm{MH} 1$ and $\mathrm{MH} 2$ tests consisted of charges detonated at the same DOB. HJ1 used the same explosive weight and backfill material as $\mathrm{MH1}$ and $\mathrm{MH} 2$ but was detonated at the surface $(\mathrm{DOB}=0 \mathrm{~m})$. HJ2 consisted of the same explosive weight and backfill material as $\mathrm{MH1}, \mathrm{MH}$, and HJ1 but differed because a concrete slab was buried a known depth in the backfill for the purpose of investigating reflection, propagation, and transmissivity of the concrete slab. Each of the four field experiments included soil stress gages and accelerometers. However, none of the experiments were conducted with a charge buried to a fully coupled depth. The lack of a fully coupled baseline experiment in the series makes it difficult to develop comparisons between recorded peak stresses and particle velocities for partially coupled and fully coupled events.

\section{Historical Data Comparisons and Interpretations in Terms of Coupling Factors}

This section presents an interpretation in terms of coupling factors of the historical data obtained during the $\mathrm{MH} 2$ and $\mathrm{HJ1}$ research experiments. $\mathrm{MH1}$ data are not included because a large percentage of the gages were either clipped (measured peak values exceeded the gage range) or produced reportedly questionable values. $\mathrm{HJ} 2$ data are not included in the comparisons due to the potential influence of the concrete slab buried in the backfill. All data shown in this section are presented in normalized form. Two coupling factors were defined: the coupling factor for the peak stress, $f_{s}$, and the coupling factor for the peak particle velocity, $f_{v}$, which can be expressed as

$$
f_{s}=\frac{s_{e}}{s_{c}} ; \quad f_{v}=\frac{v_{e}}{v_{c}}
$$

where $s_{e}$ is the experimental peak stress for partially coupled detonations, $s_{c}$ is the peak stress for fully coupled detonations, $v_{e}$ is the experimental peak particle velocity for partially coupled detonations, and $v_{c}$ is the peak particle velocity for fully coupled detonations. Since none of the four historical experiments contained a weapon buried to a fully coupled DOB, the values of fully coupled peak stress, $s_{c}$, and peak particle velocity, $v_{c}$, were calculated in this paper by using the software package ConWep [15]. ConWep allows the use of multiple input parameters for calculation of both fully coupled and partially coupled ground shock. ConWep has a soil setting DSOIL-4, which represents tabular data generated from experiments using Socorro plaster sand and high fidelity

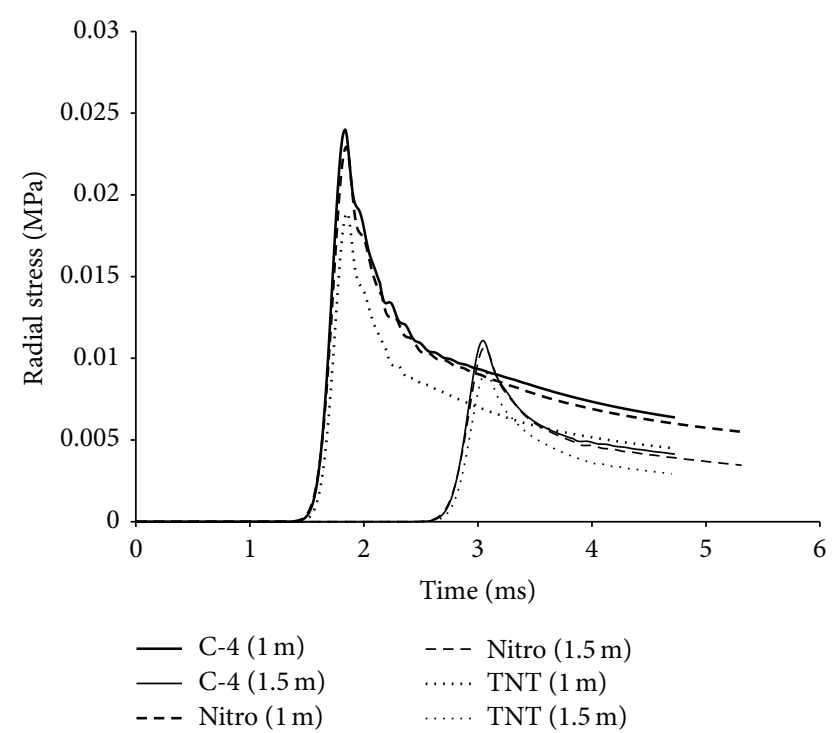

FIGURE 1: Explosive equivalency comparison of TNT, nitro, and C-4.

numerical calculations that utilize fits to the Simple Hybrid Elastic-Plastic (SHEP) model [16] for Socorro plaster sand. The SHEP fits are generated from high pressure triaxial and uniaxial test data of Socorro plaster sand samples from the aforementioned experiments. ConWep itself does not contain any soil models. Additionally, ConWep does not contain an explosive model for nitromethane (nitro). To calculate a fully coupled event similar to the partially coupled experiments, an equivalency calculation was made from nitro to an alternative explosive contained in ConWep's explosive library. The software SABER [17] was used to compare nitro to Composition $4(\mathrm{C}-4)$ and trinitrotoluene (TNT). Three separate calculations were conducted using SABER: one with C-4, one with nitro, and one with TNT; the latter of which is the explosive typically used for equivalency calculations. For each calculation, the explosive weight input was $2.27 \mathrm{~kg}$ with a coupling factor of 1 (fully coupled). A plot showing the radial stress time histories for ranges of $1.0 \mathrm{~m}$ and $1.5 \mathrm{~m}$ for all the three cases is shown in Figure 1. Based on this output, C4 compares favorably with nitro and is approximately 1.029 times as energetic with respect to ground shock. Therefore, C-4 was used as the equivalent explosive at a ratio of 0.972 times the nitro explosive weight in the ConWep fully coupled calculations of peak stresses and particle velocities.

Table 1 shows the peak stress and particle velocity values calculated using ConWep at the program default ranges using an equivalent charge of $\mathrm{C}-4$ with a coupling factor of 1 . By specifying the ranges of the ConWep calculations to match the ranges of the gages in the $\mathrm{MH} 2$ and $\mathrm{HJ} 1$ field experiments, the ratio of the experimental peak stress to the calculated peak stress and the ratio of the experimental peak velocity to the calculated peak velocity were determined based on (3). Using the fully coupled values obtained from ConWep, plots of the coupling factor as a function of the normalized DOB were generated for the MH2 and HJ1 experiments. Figures 2 and 3 compare the obtained coupling factors for peak stresses and peak particle velocities, respectively, with the coupling factor 
TABLE 1: Fully coupled values of peak soil stress and particle velocity versus range using an equivalent C-4 charge from ConWep.

\begin{tabular}{|c|c|c|c|c|c|c|}
\hline Range (m) & 1.22 & 1.85 & 2.82 & 4.29 & 6.54 & 9.97 \\
\hline Calculated peak stress $(\mathrm{MPa})$ & 301.6 & 77.2 & 21.2 & 6.9 & 2.7 & 1.1 \\
\hline Calculated peak particle velocity $(\mathrm{m} / \mathrm{s})$ & 404.5 & 108.0 & 31.0 & 10.5 & 4.2 & 1.9 \\
\hline
\end{tabular}

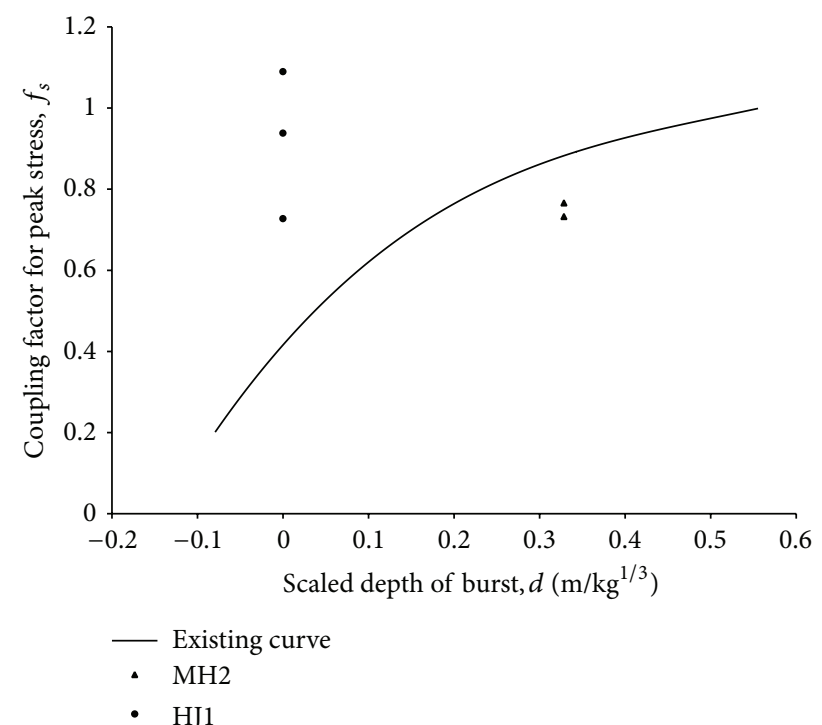

FIGURE 2: Coupling factor, $f_{s}$, calculated from MH2 and HJ1 using peak soil stress.

curve for soil given in U.S. Army design manual TM 5-855-1 [11].

Investigation of Figures 2 and 3 leads to several interesting observations. Variability of the $\mathrm{MH} 2$ data is significantly greater than that of the HJ1 data. This phenomenon can be attributed to the greater number of data points obtained during HJ1. Additionally, data scatter can be attributed to the wide variety of ranges at which gages were placed. These data also support the hypothesis suggested by Ehrgott Jr. [3] that different coupling factors should be used for soil stress and particle velocity. The comparisons presented in Figures 2 and 3 also highlight the significant differences between the experimental data points and the design curve for the coupling factor for soil. Based on these results, it was concluded that additional test data for a particular soil are required to develop reliable coupling factors for near-surface detonations.

\section{Ground Shock Coupling Factor Field Experiments}

4.1. Test Configuration and Construction Sequence. A set of ground shock experiments was recently conducted by the U.S. Army Engineer Research and Development Center (ERDC) to further investigate the adequacy of the coupling-factor approach to shallow-buried or near-surface detonations. A single testbed was constructed to conduct all the field experiments. The testbed measured $3.66 \mathrm{~m}$ by $3.66 \mathrm{~m}$, was $1.83 \mathrm{~m}$ deep, and was placed in the natural soils found at

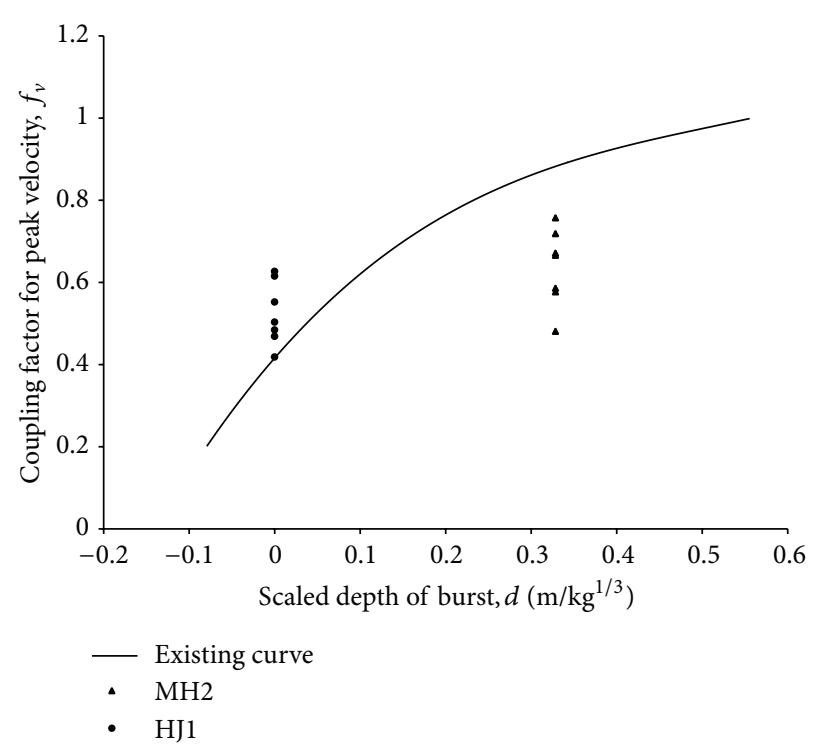

FIGURE 3: Coupling factor, $f_{v}$, calculated from MH2 and HJ1 using peak particle velocity.

Range 19, Ft. Polk, LA (see Figure 4). The pit was filled with a well-characterized dry sand backfill that had previously undergone extensive testing at the ERDC Geotechnical and Structures Laboratory (GSL). The soil used for the experiments is a poorly graded sand (SP), according to the Unified Soil Classification System (USCS) [18], and is referred to in the remainder of the paper as "concrete sand." The concrete sand was placed in 6-in. loose lifts and compacted with three passes of a vibratory plate compactor until the pit was filled. For each lift, the quality control inspector obtained five measurements with a Troxler nuclear moisture-density gage and obtained five samples of the sand for standard oven-dry water content measurements. In addition, three microwave water content measurements were obtained in most lifts. A target dry density specification was based on a combination of field experience and the results from laboratory grainsize distribution, specific gravity, and relative density tests. A water content recommendation of 3.0 to 5.0 percent was selected so that small differences in water content would result in small differences in maximum dry densities. The laboratory determination of maximum density is an index test for a controlled compaction effort. The maximum density that is actually achieved in the field can vary above or below the standard, depending on the compaction effort exerted by the equipment being used and the backfill conditions. In this case, the equipment used and the backfilling conditions (lateral restrictions, loosening due to vibration, etc.) led to a compaction effort that produced less than the standard maximum dry density (i.e., $1.79 \mathrm{~g} / \mathrm{cc}$ ), and, therefore, the 


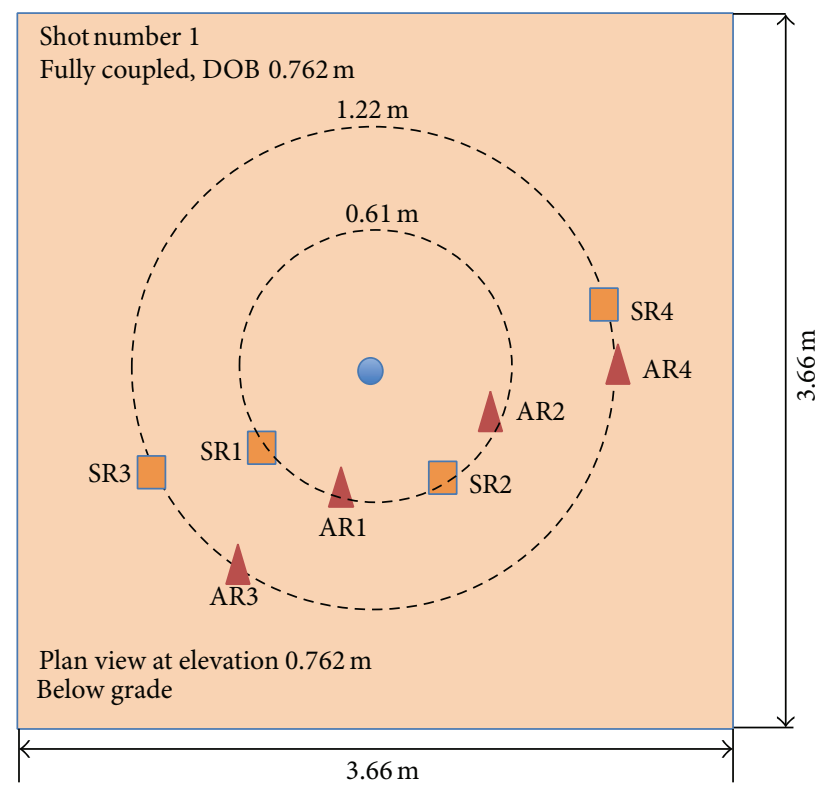

Backfill accelerometer

Soil stress gage

Spherical charge

FIgURE 4: Typical gage layout for buried detonations (plan view).

specification was adjusted below the standard curve to a target dry density between $1.65 \mathrm{~g} / \mathrm{cc}$ and $1.71 \mathrm{~g} / \mathrm{cc}$.

4.2. Backfill Instrumentation and Gage Locations. For each experiment, eight ground shock gages were placed in the backfill. Two soil stress gages and two accelerometers were installed for each experiment at distances of $0.6 \mathrm{~m}$ and $1.22 \mathrm{~m}$ from the center of gravity (CG) of the charge for a total of four stresses and four accelerometer measurements. For charges buried deeper than $0.30 \mathrm{~m}$ below ground surface, each of the gages was located at the depth of the CG of the charge and oriented to measure radial stress and acceleration along paths radiating from the $\mathrm{CG}$ of the explosive charge, as shown in Figure 4. In experiments with explosive charges near or above the surface, gages were placed along a line directly below the CG of the explosive charge and oriented vertically, as shown in Figure 5. This alternate configuration was needed to ensure that gages measured ground shock without interference from surface airblast or soil-to-surface interface disruption.

Backfill gage designations were (1) "S," representing soil stress gages or "A," representing accelerometers; (2) "R," representing gages oriented radially so that the sensing element faced the charge CG; and (3) the gage number. For example, gage "SR2" is soil stress gage number 2 oriented radially. Gages SR1, SR2, AR1, and AR2 were located at a range of $0.61 \mathrm{~m}$ from the charge; gages SR3, SR4, AR3, and AR4 were located at a range of $1.22 \mathrm{~m}$ from the charge. All data were recorded with $\mathrm{Hi}$-Technique Model 0904-4023 digital transient recorders at a sampling frequency of $500 \mathrm{KHz}$, corresponding to a data point every $2 \mu \mathrm{s}$.

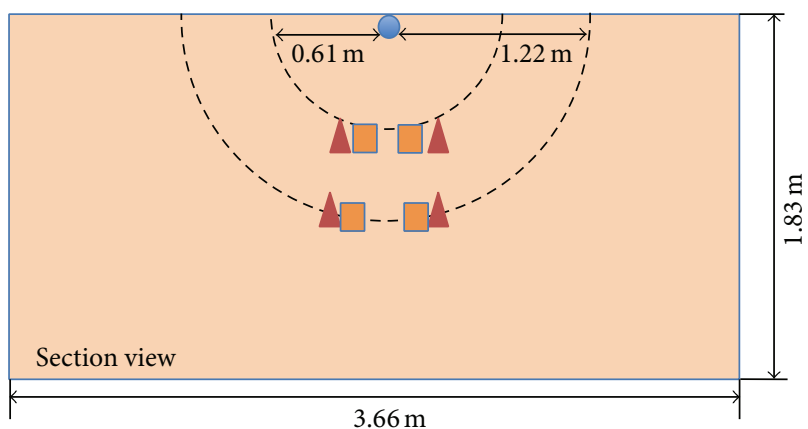

Backfll accelerometer

Soil stress gage

Spherical charge

FIGURE 5: Typical gage layout for near- and above-surface detonations (side view).

4.3. Charge Placement and Arming. For each of the buried charges, a section of plastic pipe was placed in the backfill and extended from the charge location to at least the free surface. After the backfill was completed, a 5-lb spherical C4 charge was constructed, a blasting cap was placed into the top center of the charge, and the charge was lowered into the pipe until it reached the bottom. The void space around and above the charge was backfilled with sand as the pipe was gradually pulled from the testbed. A Reynolds FS-17 firing system and Teledyne RP-83 blasting cap were used to detonate each uncased spherical charge of C-4 explosive.

\section{Experiment Matrix}

Seven experiments were conducted as part of this research effort, and each of the experiments used an identical $2.27 \mathrm{~kg}$ spherical charge of C-4 in a carefully controlled backfill of concrete sand. The DOB for each charge was varied from a fully coupled depth $(0.76 \mathrm{~m})$ to an aboveground height of $0.30 \mathrm{~m}$. Table 2 shows the pertinent information for each experiment in the matrix.

5.1. Experiment 1: Fully Coupled Detonation. Experiment 1 represented the baseline experiment and corresponded to the maximum amount of ground shock that can be obtained with a $2.27 \mathrm{~kg}$ charge of C-4 (i.e., greater DOBs would not result in more ground shock transmission). The data recorded from this experiment are the basis for which all data comparisons are presented. Detonation of $2.27 \mathrm{~kg}$ of C-4 at a DOB of $0.76 \mathrm{~m}$ resulted in a crater measuring $2.97 \mathrm{~m}$ in diameter and $0.76 \mathrm{~m}$ in depth. Soil stress and accelerometer measurements, as well as predictions made using the computer program FOIL [1], are shown in Figures 6 and 7, respectively. FOIL uses analytical fits to first-principle (SABER-1D) calculations from a spherical source of known net explosive type and weight to predict ground shock parameters for fully coupled detonations. Cube root scaling is used to allow for predictions of other explosive types. The equations in FOIL are formulated based on the theory of spherical flow fields in locking 
TABLE 2: Experiment matrix.

\begin{tabular}{lccl}
\hline Exp. number & Charge weight $(\mathrm{kg})$ & DOB (2) & Purpose \\
\hline 1 & 2.27 & 0.76 & Obtain fully coupled measurements \\
2 & 2.27 & 0.30 & Compare data points \\
3 & 2.27 & 0.07 & Investigate near-surface effects \\
4 & 2.27 & 0.0 & Investigate near-surface effects \\
5 & 2.27 & 0.07 & Verify repeatability \\
6 & 2.27 & -0.07 & Investigate near-surface effects \\
7 & 2.27 & -0.30 & Investigate near-surface effects \\
\hline
\end{tabular}

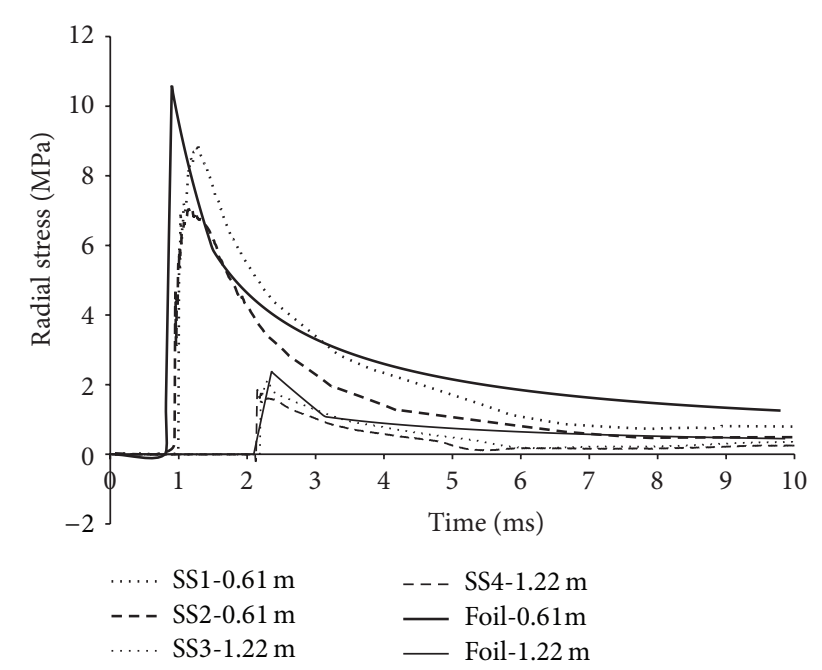

FIgURE 6: Experiment 1: soil stress measurements and prediction.

solids. Input parameters for the soil type are chosen from a material library consisting of 20 different soil types. The material types available in FOIL include sands, limestones, plastic clays, gravely clays, and silty clays with varied airfilled void ratios. The data presented in Figures 6 and 7 show that the experimental results and the numerical predictions for both the peaks and decay agree reasonably well at both ranges, while the predicted time of arrival for the shock front is slightly early for the $0.61 \mathrm{~m}$ range compared to the experimental results. This variance, along with the minor difference in predicted and recorded stress values, is likely due to minor differences in the experimental soil and the soil model used for numerical investigations and is a function of the pressure-volume relationship of each individual material (soil model).

5.2. Experiments 2 through 7: Near-Surface Detonations. Experiments 2 through 7 were conducted in similar fashion and with similarly agreeable results as experiment 1 , with some minor exceptions. In experiments 3 through 5, the soil stress gages at the $0.61 \mathrm{~m}$ range, $\mathrm{SS} 1$ and SS2, recorded significantly different peak stress values. In experiment 6 , significant noise was encountered as the shock front arrived at the $0.61 \mathrm{~m}$ range; therefore, peak soil stress values were not reliable. In all experiments, some of the acceleration records became unreliable after approximately 3 to $3.5 \mathrm{msec}$.

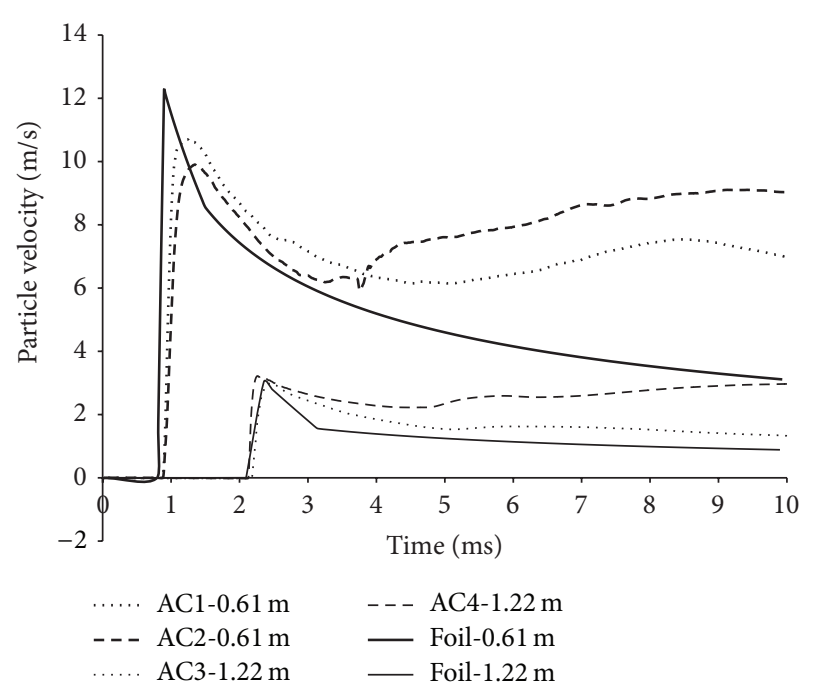

FIGURE 7: Experiment 1: particle velocity measurements and prediction.

The unreliable data are likely due to the gages being inside the crater and becoming displaced during the experiment. Plots of soil stress versus time and particle velocity versus time for experiments 2 through 7 are shown in Figures 8 and 9, respectively, for gages located at the $1.22 \mathrm{~m}$ range. These plots are representative of the variance of recorded data for the entire experimental data set.

\section{Analysis of Experimental Data}

The range of DOBs investigated during the experiments and the inclusion of an experiment with fully coupled detonation were chosen to allow the direct comparison of the peak stresses and peak particle velocities for the partially coupled to fully coupled events. These direct comparisons allow a more precise estimation of both the accuracy and sensitivity of the coupling factor as a function of DOB, range, and soil type. Peak soil stresses ranged from a maximum of $8.01 \mathrm{MPa}$ to a minimum of $3.90 \mathrm{MPa}$ while peak particle velocities ranged from a maximum of $10.3 \mathrm{~m} / \mathrm{s}$ to a minimum of $3.0 \mathrm{~m} / \mathrm{s}$ for the $0.61 \mathrm{~m}$ gage. For the $1.22 \mathrm{~m}$ gage, peak soil stressed ranged from a maximum of $2.01 \mathrm{MPa}$ to a minimum of $0.38 \mathrm{MPa}$, while peak particle velocities ranged from a maximum of $3.1 \mathrm{~m} / \mathrm{s}$ to a minimum of $1.2 \mathrm{~m} / \mathrm{s}$. Maximum peak soil stress and peak particle velocity occurred at the 
TABLE 3: Peak values of soil stress and particle velocity obtained from experimental data.

\begin{tabular}{lccc}
\hline Exp. number & Range $(\mathrm{m})$ & Peak soil stress $(\mathrm{MPa})$ & Peak particle velocity $(\mathrm{m} / \mathrm{s})$ \\
\hline 1 & 0.61 & $8.01(8.94,7.08)$ & $10.3(10.7,9.9)$ \\
1 & 1.22 & $2.01(2.15,1.88)$ & $3.1(3.0,3.2)$ \\
2 & 0.61 & $7.74(7.32,8.17)$ & $10.3(10.2,10.2)$ \\
2 & 1.22 & $1.52(1.30,1.74)$ & $2.4(2.3,2.6)$ \\
3 & 0.61 & $5.08(4.44,5.72)$ & $4.7(5.2,4.2)$ \\
3 & 1.22 & $1.46(1.38,1.54)$ & $2.7(1.9,3.5)$ \\
4 & 0.61 & $4.58(6.15,3.01)$ & $3.0(1.5,4.5)$ \\
4 & 1.22 & $1.17(1.20,1.14)$ & $2.0(1.8,2.2)$ \\
5 & 0.61 & $3.90(4.89,2.94)$ & $8.8(9.7,8.0)$ \\
5 & 1.22 & $0.57(0.49,0.64)$ & $2.2(2.3,2.1)$ \\
6 & 0.61 & $5.12(6.88,3.37)$ & $5.2(5.6,4.8)$ \\
6 & 1.22 & $0.38(0.39,0.37)$ & $1.2(1.1,1.3)$ \\
7 & 0.61 & $4.81(3.66,5.94)$ & $6.8(6.9,6.7)$ \\
7 & 1.22 & $0.68(0.62,0.74)$ & $1.4(1.4,1.4)$ \\
\hline
\end{tabular}

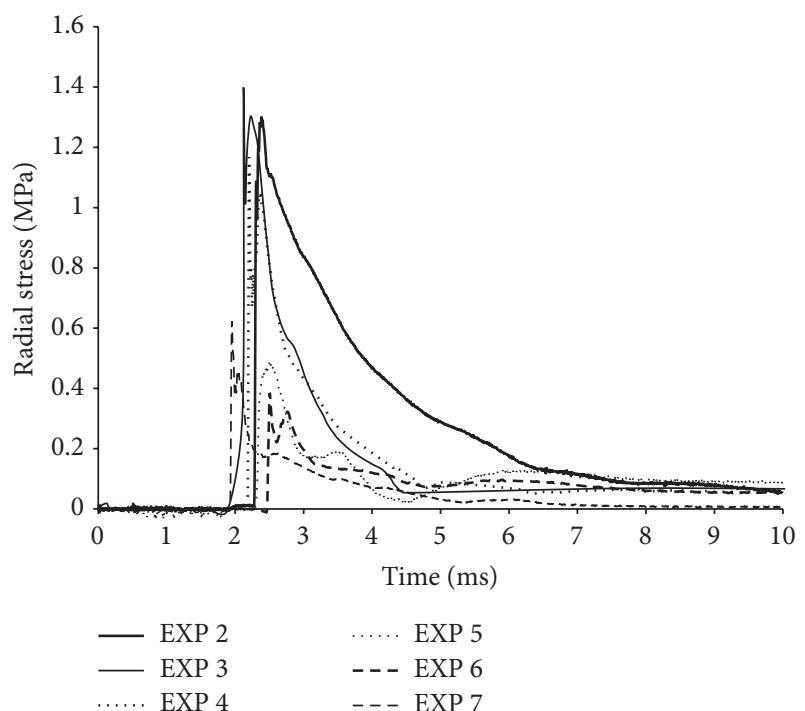

FIGURE 8: Soil stress measurements from experiments 2 through 7.

fully coupled DOB for each of the gage ranges. However, minimum peak soil stress occurred at a DOB of $0.07 \mathrm{~m}$ for the $0.61 \mathrm{~m}$ gage and at a DOB of $-0.07 \mathrm{~m}$ for the $1.22 \mathrm{~m}$ gage. This discrepancy is minor with respect to the magnitude of the minimum values and is likely due to experimental variances and minimal difference in $\mathrm{DOB}$ between the two experiments. The minimum peak particle velocities occurred at a DOB of $-0.07 \mathrm{~m}$ for both gage ranges. Using (3), coupling factors for peak stress and peak particle velocity were calculated using the experimental data from the fully coupled event (experiment 1 ) as the baseline data (i.e., as $s_{c}$ and $v_{c}$ values). Table 3 shows the peak values of soil stress and particle velocity obtained experimentally and used in the calculations for the entire experiment set. In each column, the average peak value is shown first followed by the two values from the individual gages shown in parentheses.

Using the average peak values provided in Table 3, plots of the experimental coupling factors are compared to the existing coupling factor curves in Figures 10 and 11 for soil

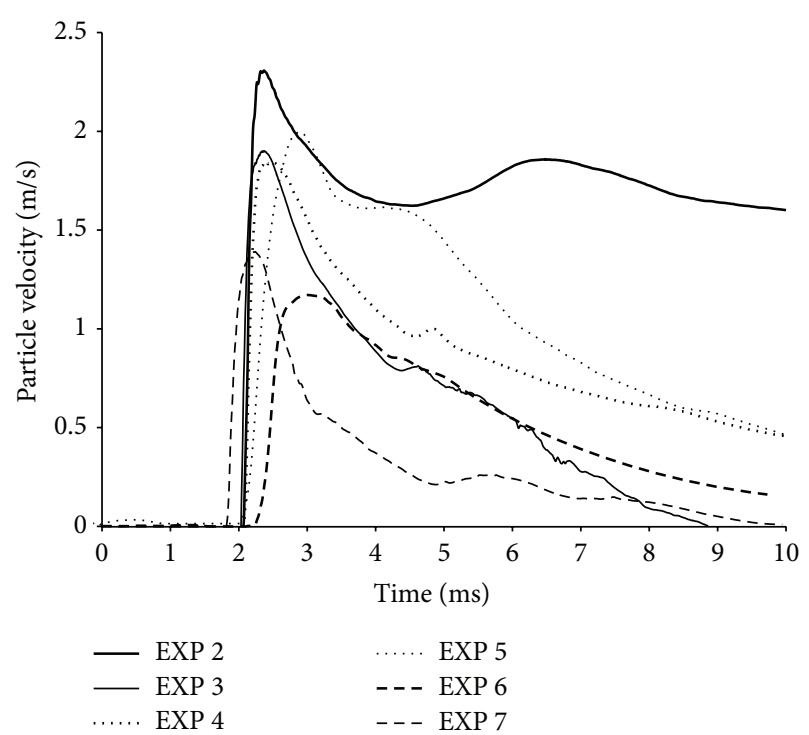

FIGURE 9: Particle velocity measurements for experiments 2 through 7.

stress and particle velocity, respectively. Figures 10 and 11 show significant variability in the collected data. Despite the scatter, it appears that the experimental values of the coupling factors are significantly greater than the values corresponding to the existing coupling factor curve. Even more interestingly, it is observed that the values of the coupling decrease for decreasing values of $d$ until they reach a minimum for $d$ close to zero. The coupling factor values begin to increase again for negative values of $d$ (i.e., for aboveground detonations).

\section{Numerical Simulations}

In conjunction with the field experiments, a numerical model was developed using the Zapotec Eulerian/Lagrangian [19] coupled code. Zapotec couples Pronto3D [20], a dynamic 3D finite element code, to CTH [21] a finite volume shock code. In the simulations performed for this study, the explosive and airblast were modeled in CTH. The sand testbed was modeled 


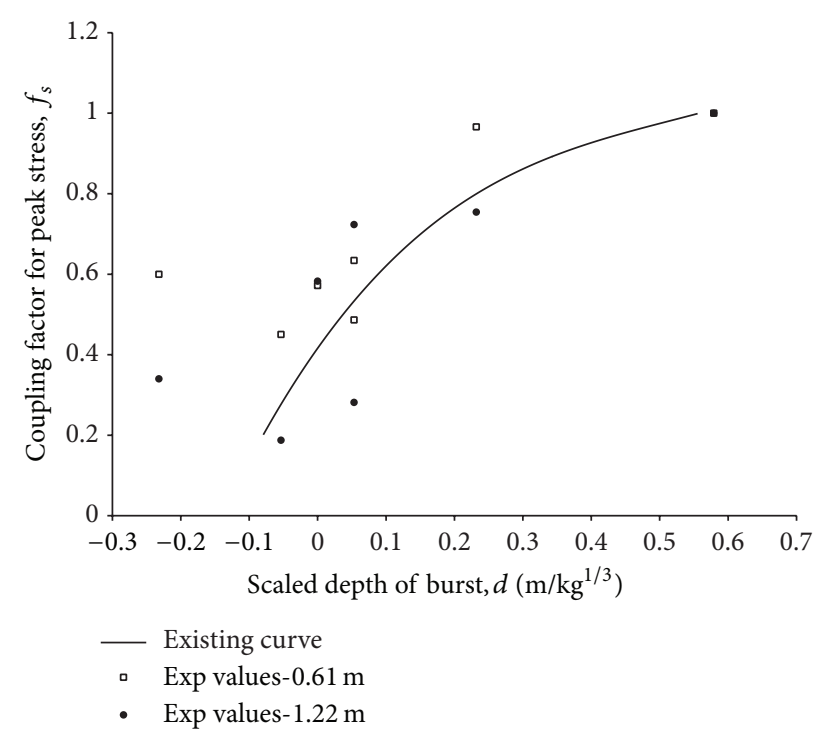

FIgURE 10: Experimental $f_{s}$ based on peak soil stress.

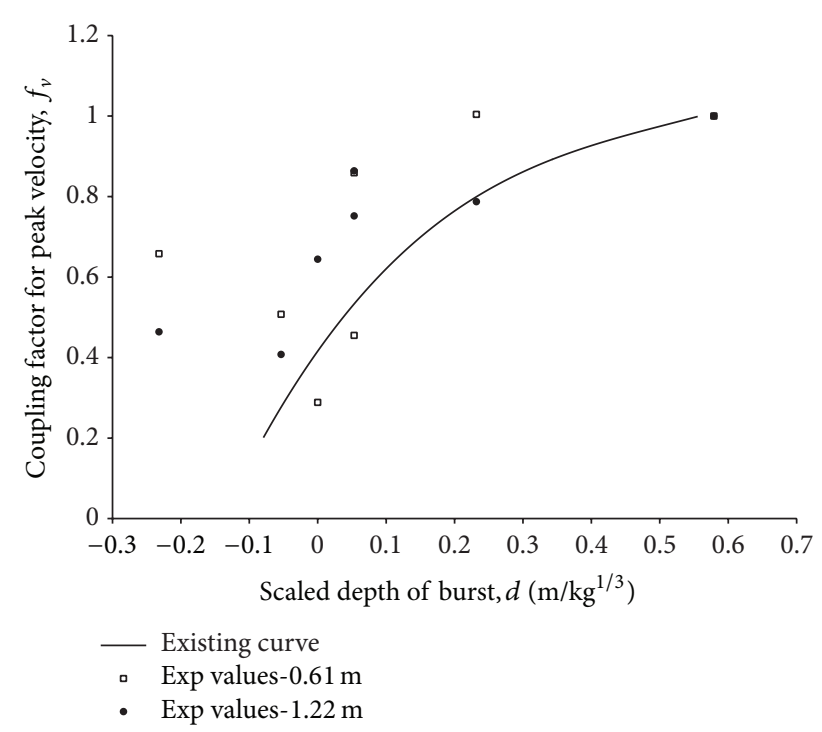

FIGURE 11: Experimental $f_{v}$ based on peak particle velocity data.

using Pronto3D. Zapotec couples the Eulerian portion of the model, in CTH, to the Lagrangian portion of the model, using Pronto3D. One advantage of using Zapotec over other mechanical simulation codes is that materials that have failed can be donated to $\mathrm{CTH}$ and treated as pure hydrodynamic materials, that is, as a material with no deviatoric strength but having a pressure volume response. By donating the material to CTH, the mass of the eroded element stays in the overall simulation. In typical element erosion schema, the eroded element's mass is lost and the accuracy of the simulation can be questioned once enough elements are eroded. A second advantage is that the eroded element's mass can still resist compression, undergo large deformations, and not slow the simulation down as a mal-formed finite element (on the Lagrangian side of the simulation).

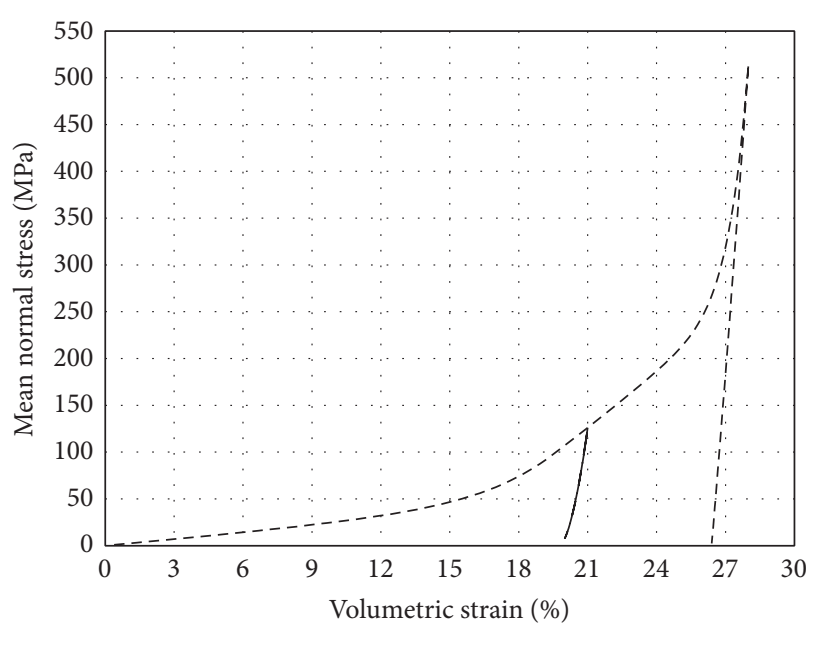

- - - 26.5\% air-filled voids (SP) concrete sand

Figure 12: Pressure-volume response for DSOIL2.

For the CTH portion of the calculation, a Jones-WilkinsLee [22] (JWL) equation of state (EOS) was used to model the detonation and pressure-volume response of the C-4 explosive products. The JWL fit for $\mathrm{C}-4$ provided by the CTH software was used for these simulations. The EOS for the air surrounding the explosive and in contact with the testbed surface is from the SESAME EOS library made by Los Alamos National Laboratory [23]. Pronto3D was used to simulate the blast response of the testbed soil. An SHEP fit to a dry soil was used to represent the mechanical behavior of the testbed material. In ERDC implementations of the SHEP model, a small library of soils is provided. The soil chosen for this effort was DSOIL2. Figures 12 and 13 show the pressure-volume response and failure envelope for DSOIL2, respectively. Figure 12 represents the mean normal stress-volumetric strain response of the considered soil as obtained from uniaxial strain tests conducted at ERDC. In these tests, the unloading paths are assumed to be elastic. The slope of the unloading phase is used to calculate the elastic modulus of the soil material model. Figure 13 represents the deviatoric stress versus confining stress response of the considered material as obtained from multiple triaxial compression tests conducted at ERDC. Tests were conducted at multiple confining pressures until failure was achieved. The failure points were fit with a curve, shown as the failure envelope in Figure 13. Figure 13 also shows uniaxial stress data, which is bounded by the failure envelope defined from the triaxial compression tests. The slope of the uniaxial stress path can be used to calculate Poisson's ratio, from which both the shear modulus and the bulk modulus of the soil can be obtained. The data shown in Figures 12 and 13 are used to define the response of the SHEP model. A detailed explanation of the procedures used to develop the pressurevolume response and failure envelopes can be found in Rohani [24]. This soil model represents a dry sand with $26.5 \%$ air-filled voids (AFV) and a minimum pressure (or cut-off pressure) of $-1.45 \mathrm{psi}$. A summary of the material models used for the materials considered in these simulations can be 
TABLE 4: Summary of material models used in numerical study.

\begin{tabular}{lccc}
\hline Component & Material model & Material fit & $\begin{array}{c}\text { Simulation } \\
\text { portion }\end{array}$ \\
\hline Explosive & JWL & C-4 & Eulerian \\
Ambient gas & SESAME EOS & Air & Eulerian \\
Testbed & SHEP & DSOIL2, sand, & Langrangian \\
Failed soil & SESAME EOS & Dry sand & Eulerian \\
\hline
\end{tabular}

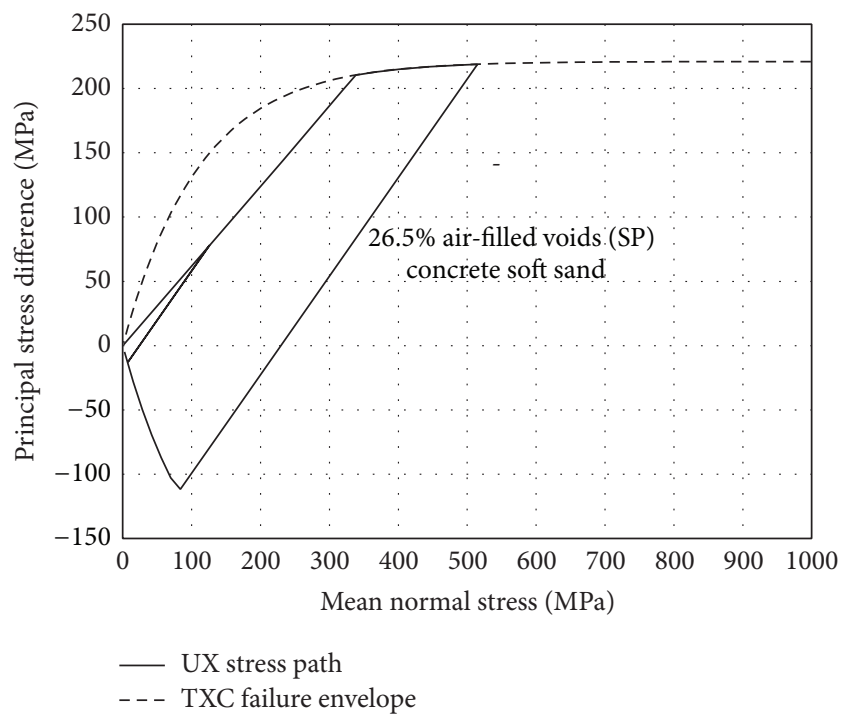

FIGURE 13: Failure envelope for DSOIL2.

found in Table 4. For the Pronto3D testbed, element failure occurs when the effective plastic strain from the SHEP model exceeds 1.7. When this exceedance is detected in the model, the corresponding element is removed from the Pronto3D model and the mass of the element is added to the $\mathrm{CTH}$ model. The eroded mass becomes a hydrodynamic material, behaving as a fluid, and is unable to withstand any deviatoric stresses.

The calculations were run for $300 \mathrm{~ms}$ of simulation time. This time span captured events from the detonation of the charge until well after the sand has ceased motion. In order to lessen the computational burden of the simulations, Zapotec was directed to turn off the CTH portion of the calculation $10 \mathrm{~ms}$ after the detonation. The numerical simulations were run on the ERDC DoD Shared Resource Center (DSRC) parallel computing on $256 \mathrm{CPU}$. Simulations were run for approximately 18 hours on the SGI Altix Ice machine designated as "Diamond."

Quarter-symmetry simulations were conducted for four of the six DOBs considered in the field experiments: 0.76, $0.30,0.07$, and $0.30 \mathrm{~m}$. Figure 14 shows the discretized mesh for the $0.76 \mathrm{~m} \mathrm{DOB}$ simulation. The surface and side boundaries of the model were modeled as transmitting boundaries. The Pronto3D sand model had a finite depth of $1.83 \mathrm{~m}$, which was equal to the depth of the backfill in the field experiments. At the bottom of the sand model, a reflective

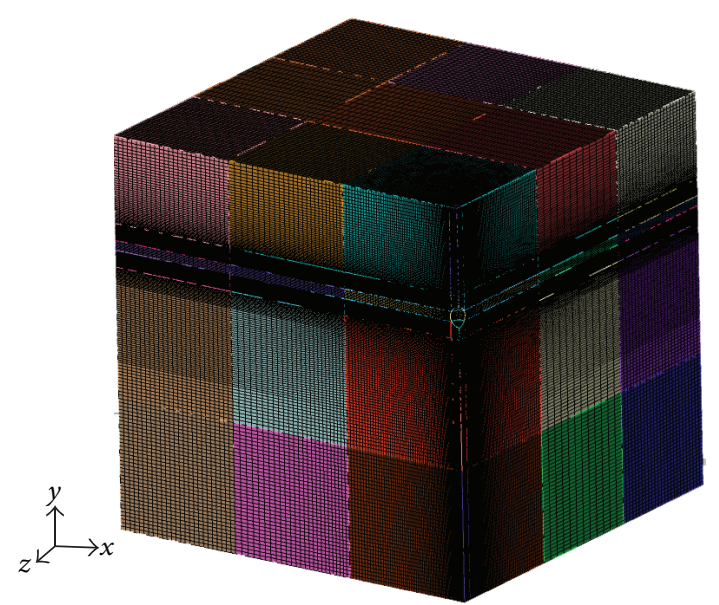

Figure 14: Discretized mesh for the $0.76 \mathrm{~m}$ DOB simulation.

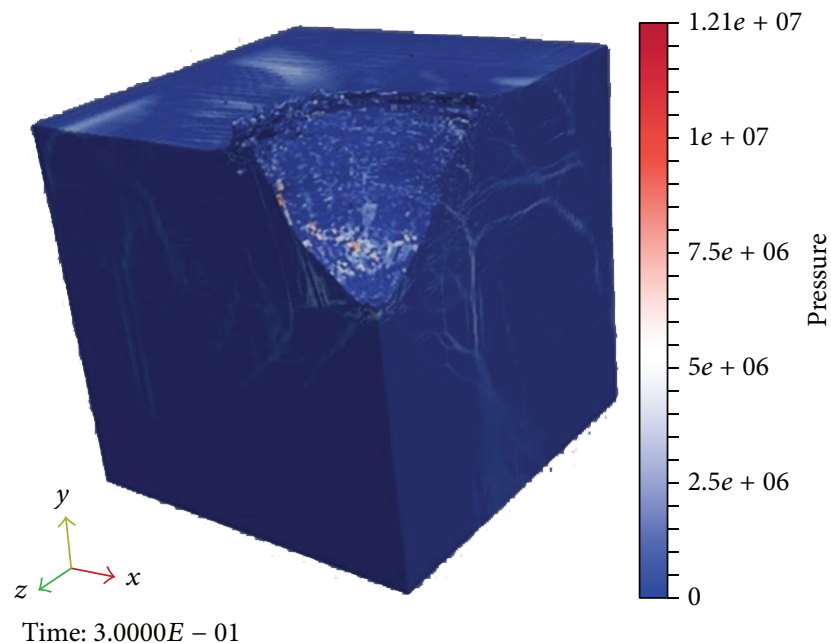

FIGURE 15: Sand model at the completion of the simulation for the $0.30 \mathrm{~m} \mathrm{DOB}$.

boundary was used to accurately simulate the change in media from the backfill material to the native soil occurring in the field experiments. Calculated soil stresses and particle velocities were saved at ranges consistent with the field experiments. Figure 15 shows the postprocessed view of the sand model at $300 \mathrm{~ms}$ for the $0.30 \mathrm{~m} \mathrm{DOB}$ simulation. The crater size and slope from the numerical simulations were somewhat different from the corresponding properties of the crater profile obtained posttest in the field experiment. These differences are a result of SHEP failure surface fit equation favoring high-pressure response. Failure surface accuracy at other pressure regimes for the SHEP model are currently being explored at ERDC. Figure 16 shows the calculated soil stress time histories from the $0.76 \mathrm{~m}$ DOB and $0.30 \mathrm{~m}$ DOB simulations at both output stations $(0.61 \mathrm{~m}$ and $1.22 \mathrm{~m}$ ). Figures 17 and 18 show comparisons of the soil stress experimental data to the numerical calculations for DOBs of $0.76 \mathrm{~m}$ and $0.3 \mathrm{~m}$, respectively. Soil stress values obtained from finite element simulation compared reasonably well with the available experimental data. 


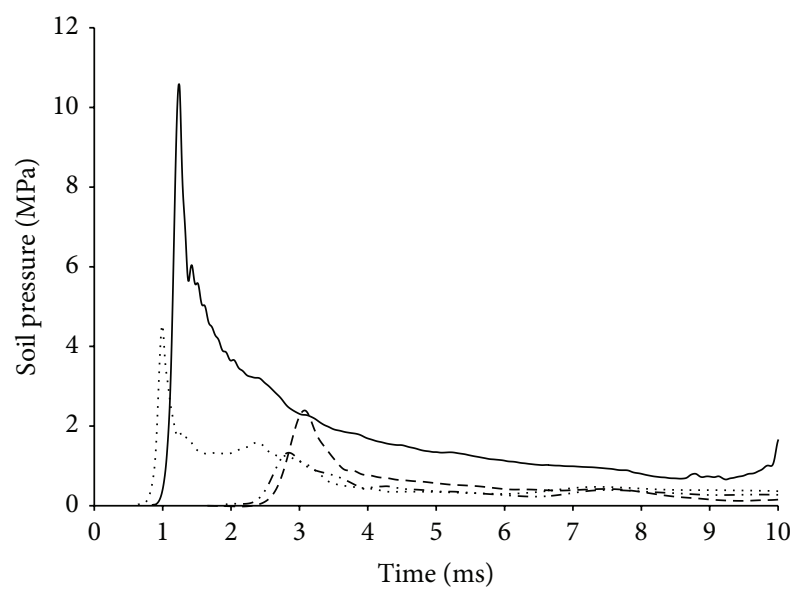

$\begin{array}{llll}- & \text { DOB } 0.76 \mathrm{~m}(0.61 \mathrm{~m}) & \ldots . & \text { DOB } 0.30 \mathrm{~m}(0.61 \mathrm{~m}) \\ \ldots-- & \text { DOB } 0.76 \mathrm{~m}(1.22 \mathrm{~m}) & \ldots & \text { DOB } 0.30 \mathrm{~m}(1.22 \mathrm{~m})\end{array}$

FIGURE 16: Soil stress output from HPC model.

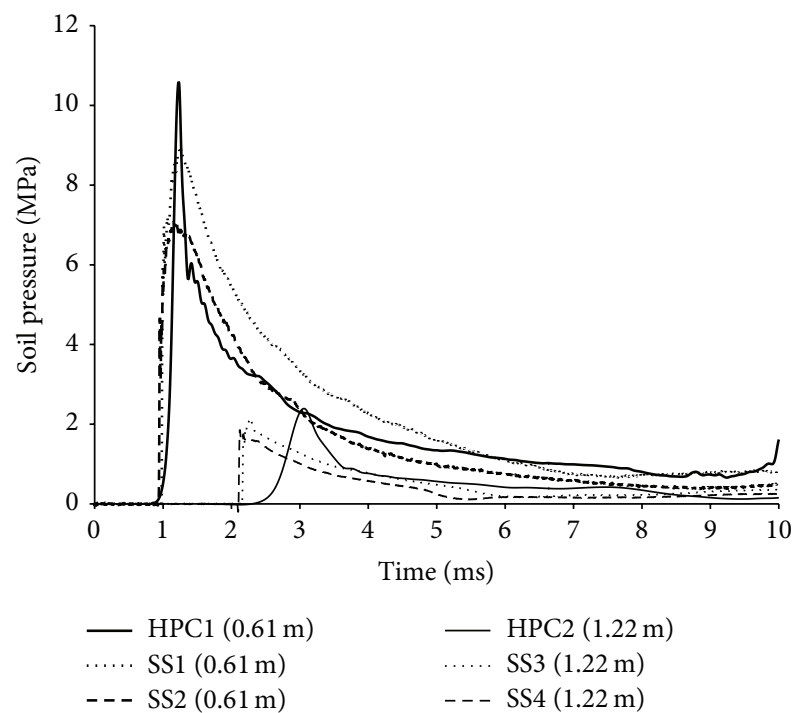

FIGURE 17: Comparison of numerical and experimental soil stress data for $0.76 \mathrm{~m}$ DOB.

\section{Summary and Conclusions}

The objective of this research effort was to investigate the adequacy of the existing coupling factor curve for a specific soil. The approach followed in this study was (1) comparing experimental data existing in the literature with the coupling factor curve currently used in the U.S. Army design manual and (2) conducting a series of field experiments designed to capture ground shock responses from a variety of DOBs in controlled backfills and comparing the results to those from a fully coupled event. In conjunction with the field experiments, numerical simulations were conducted in an attempt to reproduce the data obtained from the field experiments and investigate the adequacy of existing numerical models for use in future numerical efforts to investigate additional modeling parameters.

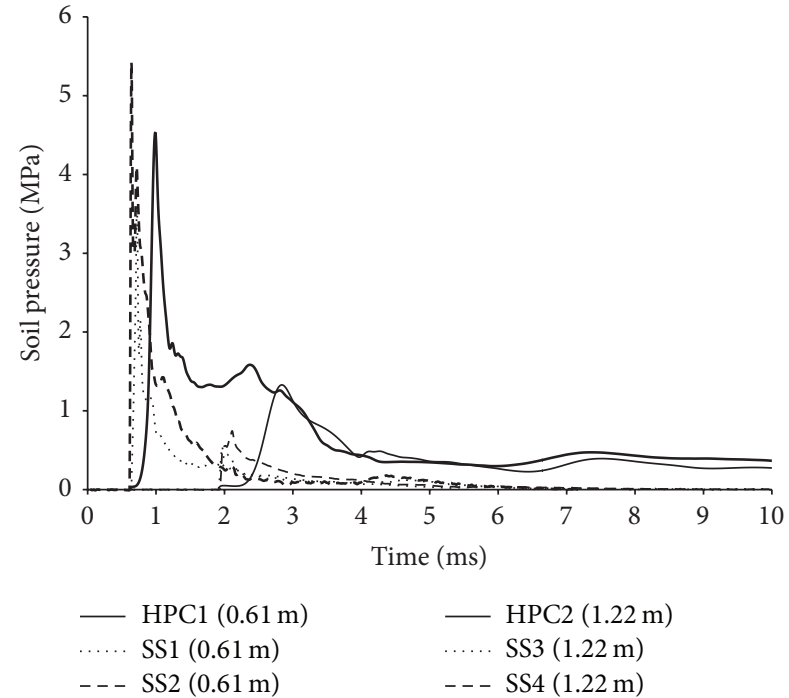

FIGURE 18: Comparison of numerical and experimental soil stress data for $0.30 \mathrm{~m}$ DOB.

Based on the historical data, no real conclusions can be made in regard to the adequacy of the existing coupling factor curve for soil. This result is due to both the lack of a fully coupled event being conducted during previous test series and a lack of varied DOBs in the historical data. However, the historical data support the hypothesis that different coupling factor curves should be used for different physical quantities.

In the field experiments, a series of tests was conducted to investigate ground shock effects in a known soil material. These tests included a varied set of DOBs, including fully coupled, partially coupled, surface, and aboveground detonations. This limited set of experimental data is characterized by significant scatter in the recorded values of both peak stress and peak particle velocity in the soil. However, based on these experiments, it appears that the coupling factor curve is inadequate for predicting ground shock response for nearsurface and aboveground detonations. The experimental data presented in this paper suggest that the current coupling factor curve provides a lower bound to the actual coupling factors for both peak stress and peak particle velocity. Thus, the existing coupling factor curve could be a conservative estimate for targeting efforts. However, for design of a friendly structure, a more conservative upper-bound coupling curve is needed. Additional numerical research to determine the applicability of upper-bound curves for design of friendly structures, along with investigation of additional soil types, is currently underway at ERDC.

A numerical model of the experiments was developed and validated against the available experimental data. The results obtained from the numerical simulations are mostly consistent with the experimental data. Differences between experimentally recorded and numerically simulated results in terms of peak values and times of arrival of the shock front were observed for some of the cases considered in this study. The relative agreement between the numerical simulation results and the experimental data does support 
the notion that a better methodology for predicting ground shock-induced loads should be developed.

Additional field experiments, perhaps at other DOBs in a concrete sand backfill and/or with other soil types, would likely aid in defining values for peak soil stresses and particle velocities that could be expected for partially coupled events. Additionally, refinement of the DSOIL2 HEP model could resolve differences in the experimental data and numerical predictions. These differences are particularly significant in the prediction of the postdetonation crater. A more comprehensive validation of a coupled numerical model, similar to Zapotec, against a detailed set of field experimental data would allow the use of modeling techniques to investigate a significantly larger range of DOBs with a much more detailed discretization. This additional research effort would provide a better description of the coupling factor curve for a given soil type and would help in defining a better methodology for predicting ground shock response for partially coupled detonations.

\section{Conflict of Interests}

The authors declare that there is no conflict of interests regarding the publication of this paper.

\section{Acknowledgments}

This research was funded by the Formerly Used Defense Sites (FUDS), Culebra Island research initiative. Permission to publish was granted by Director, Geotechnical and Structures Laboratory.

\section{References}

[1] J. E. Windham, "Ground shock prediction for conventional weapons effects," Tech. Rep. SL-96-7, U.S. Army Engineer Waterways Experiment Station, Vicksburg, Miss, USA, 1996.

[2] C. W. Lampson, "Final report on effects of underground explosions," Tech. Rep. NDRC A-479, National Defense Research Committee, Washington, DC, USA, 1946.

[3] J. Q. Ehrgott Jr., "Influence of soil properties on the aboveground blast environment from a near-surface detonation," Tech. Rep. ERDC/GSL TR-11-28, U.S. Army Engineer Research and Development Center, Vicksburg, Miss, USA, 2011.

[4] J. K. Ingram, "CENSE explosion tests program-CENSE 2, explosions in soil," Tech. Rep. N-77-6, U.S. Army Engineer Waterways Experiment Station, Vicksburg, Miss, USA, 1977.

[5] A. E. Miller, "Preliminary results report, ESSEX-1, phase 2: nuclear cratering device simulation," Tech. Rep. WES PRE-75-1, U.S. Army Engineer Waterways Experiment Station, Vicksburg, Miss, USA, 1975.

[6] W. R. Perret, A. J. Chabai, J. W. Reed, and L. J. Vortman, "Project scooter," Tech. Rep. TID-4500, Sandia Laboratory, Albuquerque, NM, USA, 1963.

[7] W. R. Perrett, "Operation Nougat, shot hard hat: free-field ground motion studies in granite," Tech. Rep. POR-1803, Sandia Laboratory, Albuquerque, NM, USA, 1963.

[8] D. C. Sachs and L. M. Swift, "Small explosion tests-project MOLE," Tech. Rep. AFSWP-291, Stanford Research Institute, Stanford, Calif, USA, 1955.
[9] R. B. Vaile Jr., Underground Explosion Tests at Dugway, Stanford Research Institute, Stanford, Calif, USA, 1952.

[10] J. L. Drake and C. D. Little, Ground Shock from Penetrating Conventional Weapons: Interaction of Non-Nuclear Munitions with Structures, U.S. Air Force Academy, Air Force Academy, Colo, USA, 1983.

[11] Department of the Army, "Fundamentals of protective design for conventional weapons," Technical Manual TM 5-855-1, Department of the Army, Washington, DC, USA, 1986.

[12] J. L. Drake, E. B. Smith, and S. E. Blouin, "Enhancements of the prediction of ground shock from penetrating weapons," in Proceedings of the 4th International Symposium on the Interaction of Non-Nuclear Munitions with Structures, Panama City Beach, Fla, USA, 1989.

[13] L. Laine and O. P. Larsen, "Numerical study of how the ground shock coupling factor is influenced by soil properties," in Proceedings of the 78th Shock and Vibration Symposium, Philadelphia, Pa, USA, 2007.

[14] C. W. Lampson, Effects of Underground Explosions, IV: Influence of Variations of Soil Type and Depths of Charge and Gauge, Office of Scientific Research and Development, Washington, DC, USA, 1945.

[15] U.S. Army Engineer Research and Development Center, Computer Code ConWep, U.S. Army Engineer Research and Development Center, Vicksburg, Miss, USA, 2002.

[16] S. A. Akers and M. D. Adley, "Constitutive models used to simulate penetration and perforation of concrete targets," in Proceedings of the ASME Pressure Vessels and Piping Conference: Structures under Extreme Loading Conditions, vol. 325, Montreal, Canada, 1996.

[17] H. D. Zimmerman, R. T. Shimano, and Y. M. Ito, "Early-time ground shock from buried conventional explosives: user's guide for SABER-PC/CWE,' Instruction Report SL-92-1, US Army Waterways Experiment Station, Vicksburg, Miss, USA, 1992.

[18] American Society for Testing and Materials, Standard Practice for Classification of Soils for Engineering Purposes (Unified Soil Classification System), Designation D2487-06e1, American Society for Testing and Materials, Philadelphia, Pa, USA, 2010.

[19] G. C. Bessette, J. K. Prentice, R. L. Bell, C. T. Vaughan, and R. A. Cole, "Zapotec: a coupled Eulerian Lagrangian computer code, methodology, and user manual, version 2.67," Sandia Technical Report SAND2003-3097, Sandia National Laboratories, Albuquerque, NM, USA, 2003.

[20] S. W. Attaway, K. H. Brown, F. J. Mello et al., "Pronto3D user's instructions: a transient dynamic code for nonlinear structural analysis," Tech. Rep. SAND98-1361, Sandia National Laboratories, Albuquerque, NM, USA, 1998.

[21] R. L. Bell, M. R. Baer, R. M. Brannon et al., "CTH user's manual and input instructions, version 6.01," Sandia Technical Report, Sandia National Laboratories, Albuquerque, NM, USA, 2003.

[22] E. L. Lee, H. C. Hornig, and J. W. Kury, "Adiabatic expansion of high explosive detonation products," Lawrence Radiation Laboratory Report UCRL-50422, Lawrence Radiation Laboratory, Livermore, Calif, USA, 1968.

[23] K. S. Holian, T-4 Handbook of Material Properties Databases, Vol. Ic, Equations of State, Los Alamos National Laboratory Report No. LA-10160-MS-v. 1C, Los Alamos National Laboratory Report, Los Alamos, NM, USA, 1984.

[24] B. Rohani, "Mechanical constitutive models for engineering materials," Tech. Rep. S-77-19, Soils and Pavements Laboratory, U.S. Army Engineer Waterways Experiment Station, Vicksburg, Miss, USA, 1977. 

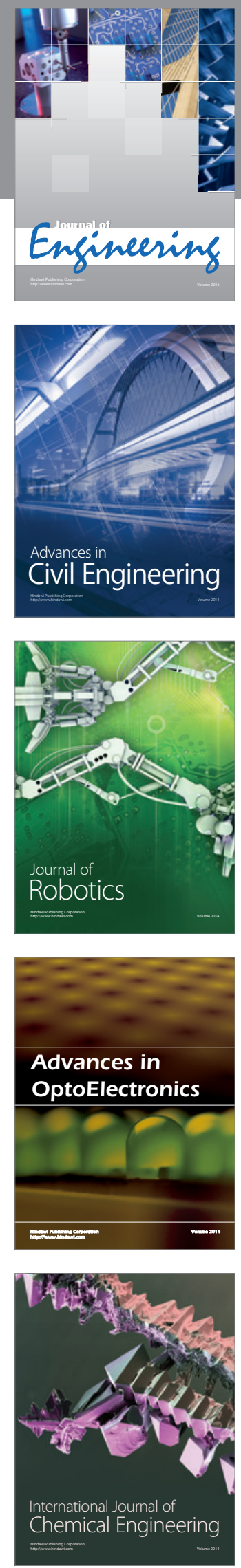

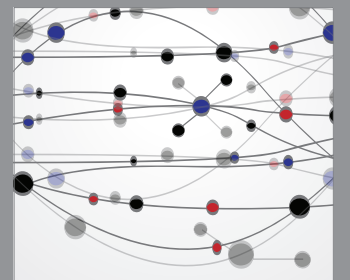

The Scientific World Journal
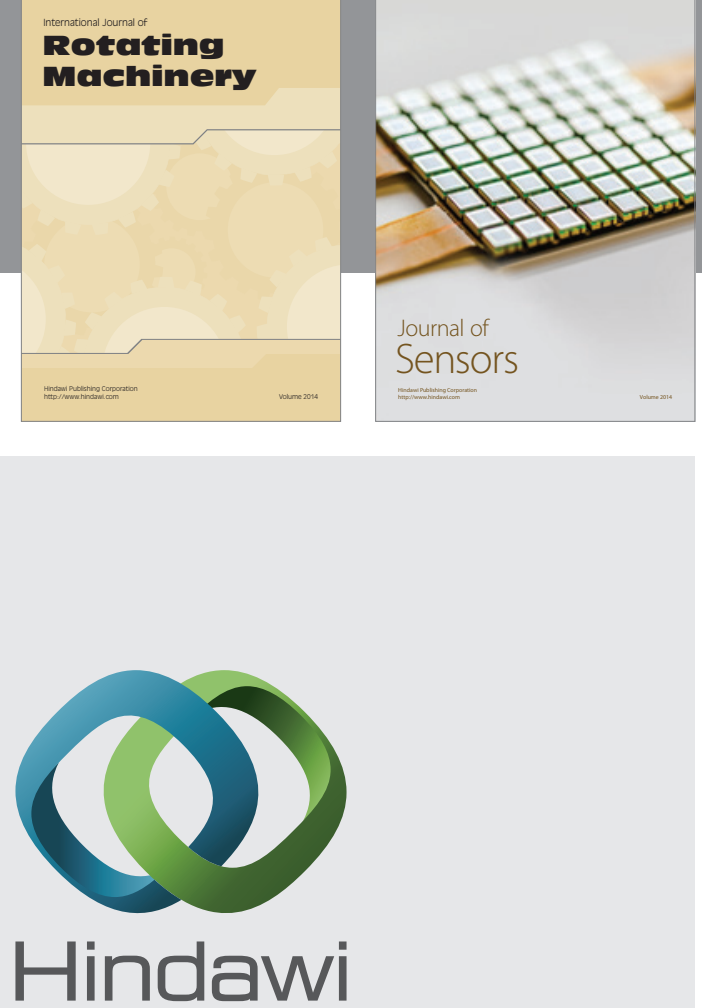

Submit your manuscripts at http://www.hindawi.com
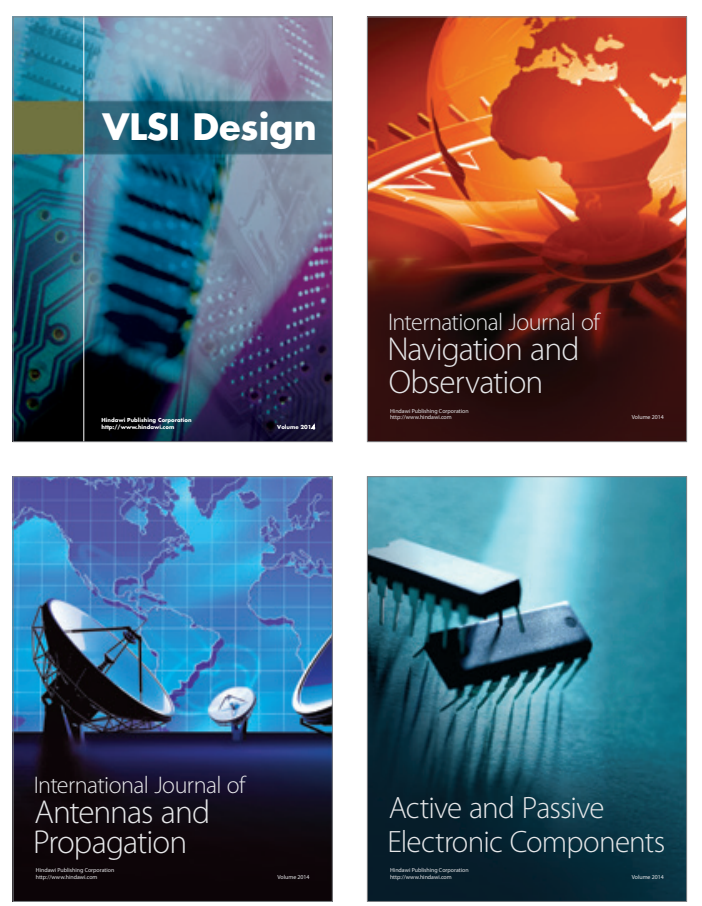
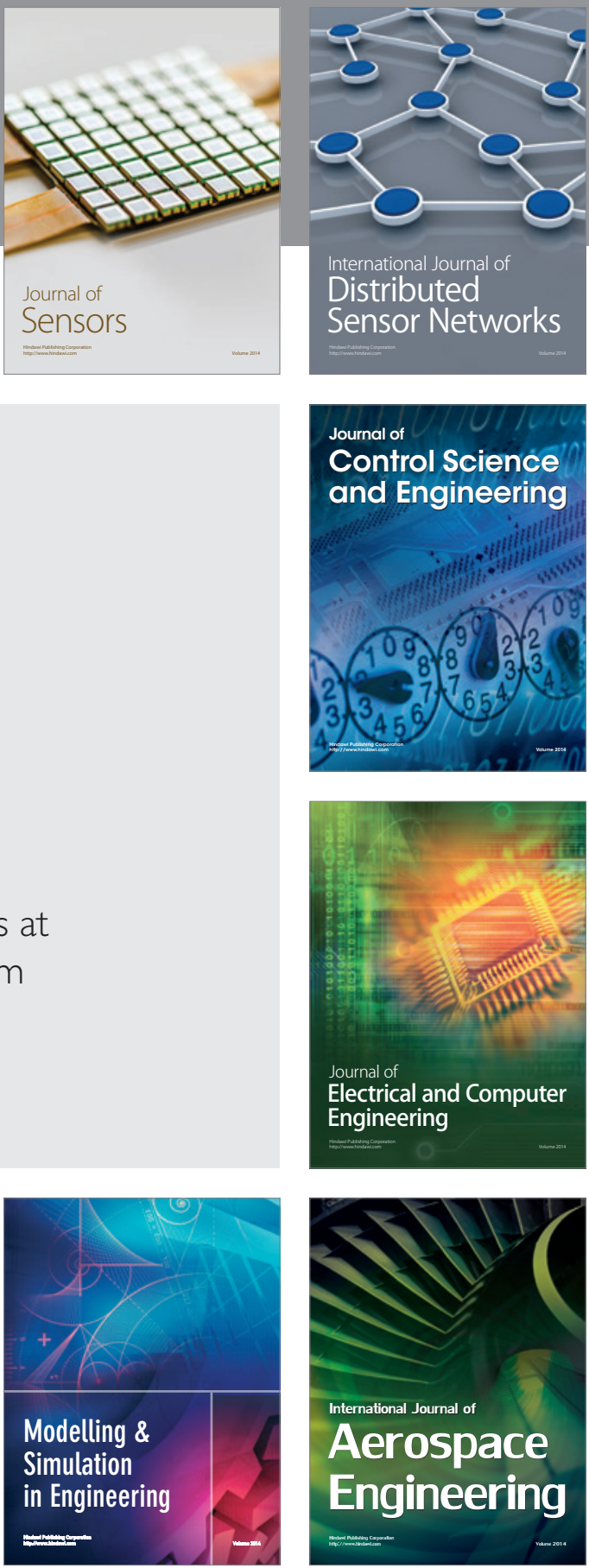

Journal of

Control Science

and Engineering
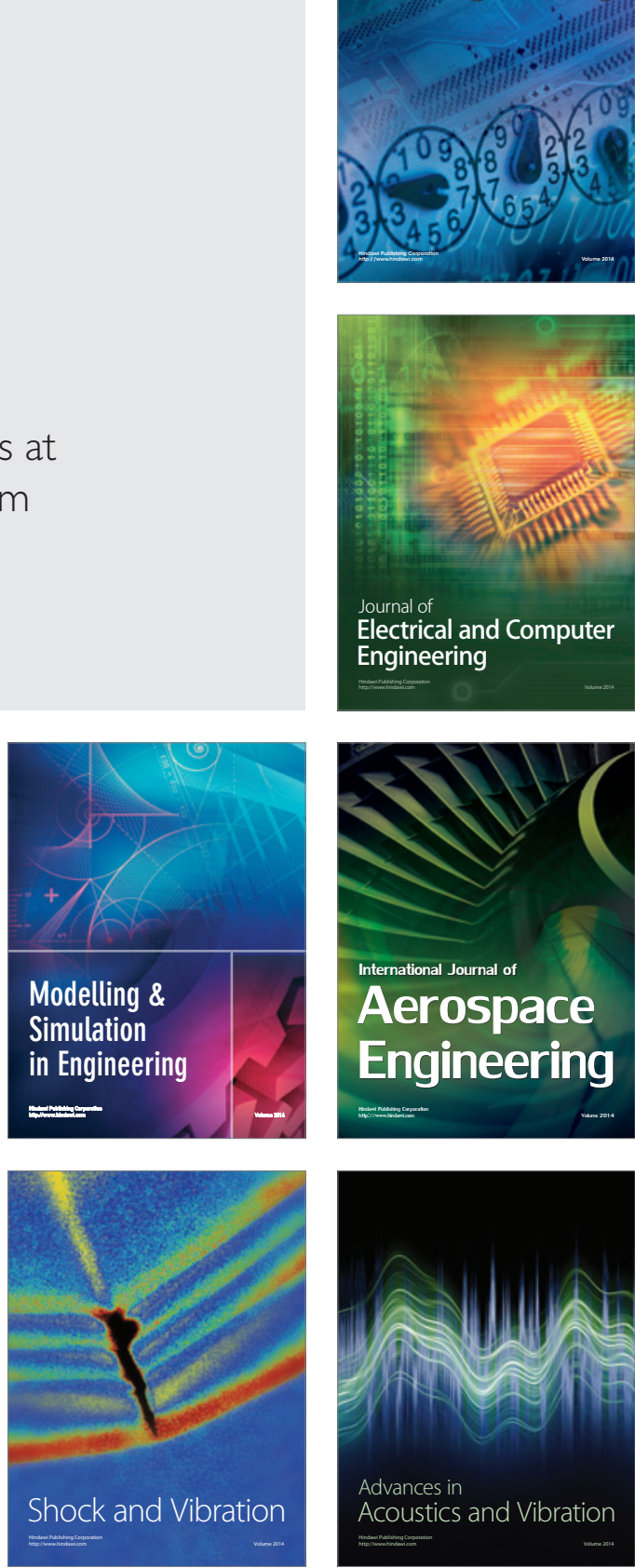